da Universidade de Nuffield uma visão das conseqüências do processo industrializante nos países subdesenvolvidos, onde perdura ainda, e com razão, a controvérsia inicial.

Não podemos negar. a significância da obra para os estudiosos da Revolução Industrial, pois encontramos nela uma abordagem muitas vezes singular e única, especialmente quando manipula as variáveis determinantes do crescimento econômico, tais como a educação e a estrutura jurídica. Porém, é bem possível que The industrial revolution and economic growth venha a servir não para elucidar a problemática da mudança e crescimento econômi$\mathrm{co}$, e sim para torná-la ainda mais confusa.

Franklin Lee Feder
Uma Visão Nova da Educaçăo: (Systems Analysis) ou Análise de Sistemas em Nossas Escolas e Faculdades

Por John Pfeifer. São Paulo, Cia. Editora Nacional, Editora da Universidade de Sã́o Paulo, 1971. Com apresentação de Anísio Teixeira.

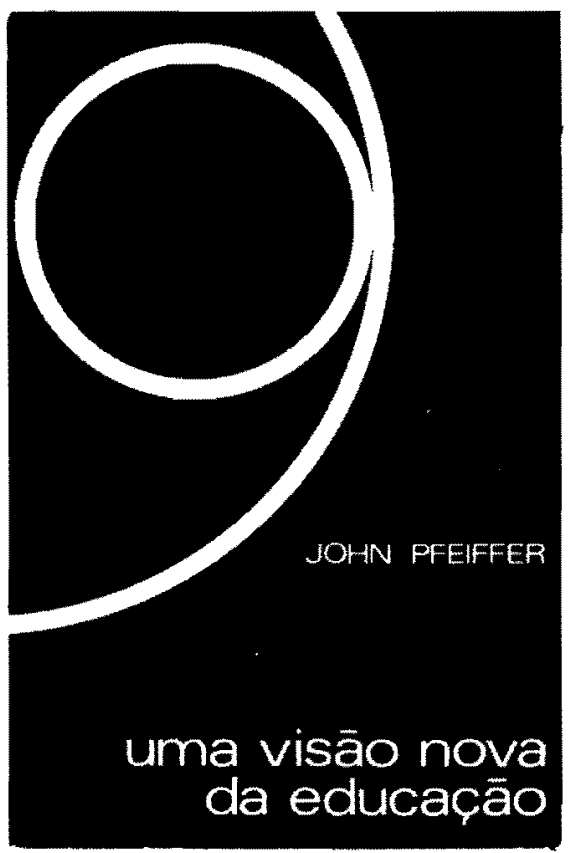

A análise de sistemas, ou análise operacional, como vem sendo chamada, diz respeito ao conjunto de processos envolvidos na utilização do computador. A sua extensão ao campo educacional, experiência bastante recente, não produziu ainda resultados definitivos, métodos precisos a serem incorporados num conjunto de conhecimentos universais a respeito da solução dos problemas educacionais. $E$, contudo, uma possibilidade que surge com amplas perspectivas de transformação dos atuais métodos de planejamento educacional, operando uma verdadeira revolução nas concepçōes tradicionais que vingam a despeito do problema.

Análise de sistemas e planejamento estão intrinsecamente ligados. E tanto um como outro só têm condiçōes de se desenvolver amplamente nos países superdesenvolvidos. Segundo Anísio Teixeira, o emprego da análise de sistemas às situaçōes sociais de determinada nação pressupõe a existência de certa homogeneida- de em tais situações, para que possam ser rigorosamente classificadas, "para se caracterizarem algumas 'uniformidades' sobre as quais se possa pensar e argumentar com lógica e plausibilida$\mathrm{de}^{\prime \prime}$. Ora, tais "uniformidades" não são encontradas, de um modo geral, nas situações sociais dos paises subdesenvolvidos. Quanto mais, de um modo particular, nas suas situações educacionais, em que cada região, cada cidade, cada escola constitui uma unidade diferente - "pois são diferentes os professores, as condiçōes da escola, os alunos, o material disponível para educação, etc." (Apresentação).

Deste modo, embora a necessidade de racionalização e de planejamento se imponha hoje em dia de modo agudo aos países subdesenvolvidos (o Brasll constitui um exemplo característico), a problemática da presente obra isto é, a extensão da análise de sistemas à educação - restringe-se, no momento, aos países superdesenvolvidos, onde já se conseguiu um elevado nível de padronização geral dos sistemas educacionais, requisito indispensável ao bom rendimento do emprego da análise operacional. Mais especificamente, o livro versa sobre as experiências norteamericanas no setor. Experiências estas, aliás, bastante escassas, visto, como nos referiamos anteriormente, a extrema novidade de tal abordagem. Devido a tal limitação, boa parte do livro discorre sobre os processos gerais envolvidos na análise operacional e sobre os vários campos em que sua utilização foi passível até hoje entre outros, destacam-se problemas militares (defesa e tática), sociais (pobreza, conflito racial, etc.), bem como problemas relativos a política internacional. Numa perspectiva histórica do desenvolvimento da análise de sistemas e sua aplicação, é interessante notar como as experiências primeiramente realizadas num determinado setor, o militar, generalizaram-se para vários outros.

O mais importante, entretanto, são os processos gerais envolvidos na análise de sistemas e a compreensão do que esta significa, abrangendo desde o próprio modo de pensar, de encarar os dados pertinentes a uma situação determirrada, até os detalhes do planejamento de pesquisa. 
A utilização da análise de sistemas consistiria "em essência, numa forma de considerar, analisar e raciocinar sobre os dados globais de uma situação..." (Apresentação), estudando-se diferentes possibilidades de solução de um mesmo problema. Tal abordagem insurge-se contra 0 procedimento clássico de se coletar dados, classificá-los e analisálos de acordo com um método fixo, preestabelecido, em que se toma a situação dada como não modificável, a ser apenas medida ou julgada.

Os processos envolvidos na análise operacional assemelhamse a um jogo. "A idéia de sistema, no fundo, é a de que a situação é uma espécie de jogo: um conjunto de peças com funções diferentes atuando e interagindo para certos resultados. No jogo, propriamente dito, as peças são fatores precisos e uniformes, as regras do jogo também precisas e uniformes, os resultados também precisos e uniformes e, daí, nada mais ter o jogador a fazer do que usar as alternativas e divertir-se com os resultados". (Apresentação)

Destas últimas afirmações surge um problema crucial: afinal, num sistema fechado, com regras fixas, onde se localiza a participação humana? É exatamente na fixação dos objetivos que se quer atingir, ponto fundamental do planejamento de pesquisa, que aquela se revela com toda a força. O computador, com seu sistema fechado e regras precisas, é o instrumento mais rápido para se conhecer os melhores meios de alcancar os fins perseguidos. Deste modo, pelo plano de ação, busca de alternativas, avaliaçãão dos resultados obtidos, enfim, pela to-

136 mada de decisões, o homem pode criar, dentro da análise de sistenas, novas regras às quais o comutador se adapta.

Todos estes pontos são discutidos pelo autor. Todavia, achamos que, nos exemplos por ele citados, a parte relativa aos objetivos perseguidos na análise de situações sociais não é suficientemente enfatizada e discutida. Tal se verifica, por exemplo, quando o autor apresenta as conclusões, ao nosso entender frágeis, de estudos por computador sobre o problema da mortalidade infantil e da probreza nos EUA: "o me-
Ihor modo de reduzir essa taxa de mortalidade é estabelecer um programa de controle da natalidade..." e "se o planejamento da família tivesse principiado uma geração atrás, os EUA teriam, presentemente, cerca de 4500 mil pobres menos do que na realidade têm".

Ora tais resultados podem constituir os meios mais eficazes para se alcançar determinados fins sociais, e não outros. O problema do controle da natalidade, que envolve questões mais complexas, não é absolutamente discutido. O autor nem sequer cogita dos problemas da elevação do inível de vida, da assistểncia à maternidade, etc., resultantes de um processo econômico mais amplo. Esta simplificação, torna a sua contribuição menos rica. O que não impede que o livro tenha um certo valor, pela novidade do tema no Brasil, como introdução aos problemas operacionais apresentados pela análise de sistemas e pela divulgação, em nosso meio, das experiências realizadas na área.

Marisa Saenz Leme

\section{Cartas ao Irmão}

Por Lafayette Rodrigues Pereira. Introdução e notas de João Camilo de Oliveira Torres; apêndice de J. Rodrigues de Almeida. São Paulo, Companhia Editora Nacional, 1968. 248 p. Col. Brasiliana, 342).
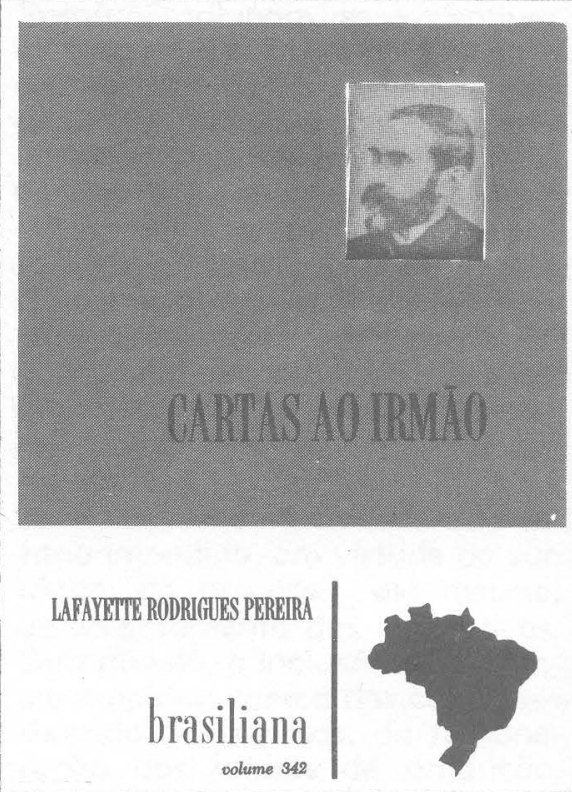

A publicação das cartas do Conselheiro Lafayette ao seu irmão Washington Rodrigues Pereira representa achega ao estudo de sua biografia, mas pequena contribuição ao conhecimento da época. $\AA$ correspondência totaliza 109 cartas e mais uma ao pai, e foram escritas de 1869 a 1895, num momento de grande agitação da vida política brasileira.

As cartas não refletem os grandes problemas do momento, revelam apenas esporadicamente certas questões de maior interesse. Porém, o que surge como constante é a pequena política provincial e as suas relações com a política da Corte, as relações entre cargos e interesses econômicos, a condição da mulher e do casamento, a nomeação do presidente da província e suas relações com os grupos locais, as eleições e os acordos, etc.

É assim que o livro nos informa mais sobre detalhes da pequena política ou do incidente menor. Os exemplos abundam no decorrer de toda correspondência: ao informar o irmão sobre o cargo de inspetor da mesa de rendas, que - presidente de Minas oferecera a Washington, Lafayette diz que é "excelente lugar; dá bastante influência na província. Só tem 